\title{
Non-ketotic hyperglycaemic chorea: a SPECT study
}

\author{
Ming-Hong Chang, Jieh-Yuan Li, Shih-Rong Lee, Chao-Yang Men
}

\begin{abstract}
:
Objective-To study regional blood flow of the striatum in non-ketotic hyperglycaemic choreic patients.

Methods-Brain SPECT was performed with intravenous injection of $20 \mathrm{mCi}{ }^{99} \mathrm{~m} \mathrm{Tc}$ hexamethylpropylene amineoxime in six non-ketotic hyperglycaemic choreic patients and 10 age matched patients with a similar level of hyperglycaemia without chorea as a control. The focal perfusion defects were analysed by visual interpretation and semiquantitative determination with reference to homolateral occipital blood flow.

Results-The measured blood flow of striatum on the contralateral side of chorea was significantly decreased.

Conclusions-Hypometabolism of the striatum is seen not only in Huntington's disease, but also in non-ketotic hyperglycaemic chorea. Hypofunction of the striatum is a possible common pathogenesis in the development of contralateral chorea in different diseases. Furthermore, the sensitivity and reliability of SPECT is as good as PET in assessing choreic patients.
\end{abstract}

(F Neurol Neurosurg Psychiatry 1996;60:428-430)

Keywords: hyperglycaemia; chorea, SPECT

Chorea may be due to a wide variety of degenerative, vascular, metabolic, or toxic disorders involving the CNS, in which dysfunction of the basal ganglia, particularly of the striatum, is generally assumed to be responsible. Therefore, various structural lesions in the contralateral subthalamic nucleus ${ }^{1-3}$ and pallidosubthalamic pathway seem to play a critical part with acute vascular accident being the most common pathological process. ${ }^{3}$ In regard to the metabolic origin of chorea, thyrotoxicosis and dysfunction of glucose metabolism can also cause this hyperkinetic involuntary movement. ${ }^{4-9}$

Non-ketotic hyperglycaemia may be associated with a wide variety of neurological abnormalities, ${ }^{1011}$ of which chorea is a rare presentation.

Recently, PET has been used to measure local cerebral metabolism and has been shown to be useful in the detection of basal ganglia dysfuction in Huntington's disease and other hereditary choreas. ${ }^{12-16}$ To date, no report has used imaging techniques to systematically examine non-ketotic hyperglycaemic choreic patients . Furthermore, no study has evaluated the sensitivity of SPECT in the detection of focal perfusion defect in non-ketotic hyperglycaemic chorea.

Therefore, we studied six patients who had typical manifestations of hemichorea or generalised chorea due to hyperglycaemia and performed SPECT to show whether a similar pathophysiology of hypometobolism or hypoperfusion of the striatum also occurs in nonketotic hyperglycaemic chorea.

\section{Materials and methods}

Six patients (four men, two women) with an age range from 58 to 71 presented with either hemichorea (five patients) or generalised chorea (one patient). Besides chorea, these six patients were all characterised by pronounced hyperglycaemia, and an increase in haemoglobin Alc concentration and serum osmolality. Ketone bodies were present in traces or absent. The patients were referred for ${ }^{99 \mathrm{~m}} \mathrm{Tc}$ hexamethylpropylene amineoxime (HMPAO) brain SPECT. Those who clearly had underlying diseases causing chorea-for example, hyperthyroidism, hereditary disorders, or lesions shown by MRI over the appropriate anatomic locus to contribute to chorea-were excluded. Another 10 age matched diabetic patients with a similar level of hyperglycaemia and an increase in $\mathrm{HbAlc}$ without chorea served as controls.

Brain SPECT (Elscint Apex CT system) was performed after intravenous injection of $20 \mathrm{mCi}{ }^{99 \mathrm{~m}} \mathrm{Tc}-\mathrm{HMPAO}$ with valium (5-10) $\mathrm{mg}$ for sedation and reduction of movement artifacts; however, the chorea was not completely abolished at examination. Data were acquired with a single headed rotating gamma camera (Orbiter; Siemens) with a low energy, all purpose, and high resolution collimator. Total acquisition angle was $360^{\circ}$, with 60 projections of $30 \mathrm{~s}$ each, and a $64 \times 64$ matrix and spatial resolution for tomographic images of about $12 \mathrm{~mm}$ for the Siemens camera. Each study required 20 minutes for data collection and contained about 2 million counts. Reconstruction was performed by a standard back projection using a Butterworth filter. Horizontal slices as well as sagittal and coronal slices, $8 \mathrm{~mm}$ thick, were obtained. Analysis was performed both visually and quantitatively.

\section{VISUAL ANALYSIS}

All SPECT studies were reviewed by two nuclear medicine physicians who were unaware of the patient's clinical state and were experienced in interpreting brain SPECT studies. If 
Table 1 Clinical findings and laboratory results

\begin{tabular}{|c|c|c|c|c|c|c|c|}
\hline $\begin{array}{l}\text { Patient } \\
\text { No }\end{array}$ & Age/sex & $\begin{array}{l}\text { Limbs with } \\
\text { chorea }\end{array}$ & $\begin{array}{l}\text { Sugar at } \\
\text { admission } \\
\text { (mg/dl) }\end{array}$ & $\begin{array}{l}\text { Serum } \\
\text { osmolality } \\
\text { (mosmol) }\end{array}$ & $\begin{array}{l}\text { HbA1c } \\
\text { level } \\
(\%)\end{array}$ & $\begin{array}{l}\text { Use of } \\
\text { haloperidol }\end{array}$ & $\begin{array}{l}\text { Remission of chorea } \\
\text { after control of sugar }\end{array}$ \\
\hline $\begin{array}{l}1 \\
2 \\
3 \\
4 \\
5 \\
6\end{array}$ & $\begin{array}{l}68 / \mathrm{M} \\
58 / \mathrm{F} \\
71 / \mathrm{M} \\
63 / \mathrm{M} \\
67 / \mathrm{F} \\
70 / \mathrm{M}\end{array}$ & $\begin{array}{l}\text { RUL and RLL } \\
\text { RUL and RLL } \\
\text { RUL and RLL } \\
\text { LUL and LLL } \\
\text { LUL and LLL } \\
\text { RUL,LUL,LLL } \\
\text { and facial m. } \\
\text { (more violent } \\
\text { on left) }\end{array}$ & $\begin{array}{l}457 \\
354 \\
413 \\
512 \\
289 \\
315\end{array}$ & $\begin{array}{l}321 \\
308 \\
325 \\
337 \\
307 \\
313\end{array}$ & $\begin{array}{l}10.5 \\
11.2 \\
10.9 \\
11.3 \\
10 \cdot 3 \\
10.7\end{array}$ & $\begin{array}{l}\text { No } \\
\text { No } \\
\text { No } \\
\text { Yes } \\
\text { No } \\
\text { Yes }\end{array}$ & $\begin{array}{l}\text { Yes } \\
\text { Yes } \\
\text { Yes } \\
\text { No } \\
\text { Yes } \\
\text { No }\end{array}$ \\
\hline
\end{tabular}

$\mathrm{RUL}=$ right upper limb; RLL = right lower limb; LUL = left upper limb; LLL = left lower limb.

Table 2 SPECT findings for patient group

\begin{tabular}{lllllll}
\hline \multirow{2}{*}{$\begin{array}{l}\text { Patient } \\
\text { no }\end{array}$} & $\begin{array}{l}\text { Visual } \\
\text { analysis }\end{array}$ & \multicolumn{2}{l}{ Quantitative analysis } \\
\cline { 3 - 7 } & LS/LO & RS/RO & LTh/LO & RTh/RO & LO/RO \\
\hline 1 & $\downarrow$ in LS & 0.842 & 0.934 & 0.927 & 0.931 & 1.01 \\
2 & $\downarrow$ in LS and T & 0.871 & 0.947 & 0.921 & 0.917 & 0.98 \\
3 & $\downarrow$ in LS & 0.851 & 0.923 & 0.923 & 0.927 & 1.02 \\
4 & $\downarrow$ in RS & 0.918 & 0.864 & 0.924 & 0.932 & 0.99 \\
5 & $\downarrow$ in RS & 0.938 & 0.877 & 0.931 & 0.934 & 0.97 \\
6 & $\downarrow$ in both S & 0.863 & 0.854 & 0.883 & 0.872 & 0.99 \\
& and Th & & & & & \\
\hline
\end{tabular}

L = Left; $R=$ right; $S=$ striatum; $T=$ temporal lobe; $T h=$ thalamus; $O=$ occipital lobe; $\downarrow=h$ decrease in blood flow (the ratio is expressed as the investigated regional blood flow referenced to that over the homolateral occipital area).

there was a disagreement, they would discuss it to reach a consensus.

\section{SEMIQUANTITATIVE ANALYSIS}

Uptake of ${ }^{99 m}$ Tc-HMPAO in striatum, thalamus and occipital regions was quantified by placing appropriate regions of interest on positions standardised under MRI guidance. All quantitative analysis was performed by two observers blinded to the clinical states.

Static HMPAO SPECT did not allow absolute quantification of regional cerebral blood flows. Semiquantitative analysis could be performed by comparing uptake in the region under evaluation with uptake in a region unaffected by the disease process. The occipital area was pathologically spared in chorea and therefore it was suitable as a referenced region in this study. We expressed HMPAO uptake for each region as the ratio of the uptake in that region to that in the occipital area. As there were no significant differences between uptake in the left and right occipital area, both sides were included in comparisions.

Series of transaxial section of SPECT in patient 1 show markedly asymmetric blood perfusion with a decreased flow over the left striatum.
Comparision between the ratio of the uptake in striatum contralateral to chorea and that homolateral to chorea was made with Student's $t$ test. Comparision between non-ketotic hyperglycaemic choreic patients and controls was also made.

\section{Results}

\section{CLINICAL DATA}

Table 1 summarises the clinical presentations and biochemical results. All six patients had pronounced hemichorea or generalised chorea, non-ketotic hyerglycaemia, an increase of haemoglobin Alc concentration, and hyperosmolality. The chorea of four patients was not markedly violent and remitted after correction of hyperglycaemia and hyperosmolality. The other two patients received haloperidol (2-4 mg per day) in addition to control of blood sugar. Although chorea persisted after control of blood sugar, it subsided within one week with continued use of haloperidol.

\section{VISUAL ANALYSIS}

Brain SPECT clearly showed decreased blood perfusion of the striatum contralateral to the side of choreic movement. Patient 2 also had mildly decreased perfusion over the left temporal region and patient 6 had bilateral reduction of flow over the thalamus. Table 2 and fig 1 show the result of qualitative analysis of SPECT. There was no perfusion defect in the control group of age matched and equivalent hyperglycaemic diabetic patients.

\section{SEMIQUANTITATIVE ANALYSIS}

Table 2 summarises results for the the ratio of blood flow in the striatum and thalamus referenced to that in the homolateral occipital region. The mean (SD) of the ratio in the striatum contralateral to choreic movement was $0.860(0.012)$ and that for the homolateral to chorea side was $0.932(0.012)$. By contrast with the patient group, the mean (SD) of the ratio of striatal blood flow in the controls was 0.937 $(0.013)$ on the left and $0.934(0.01)$ on the right.

When comparing the difference of the ratio of the striatal blood flow contralateral and homolateral to choreic sides, a significant decrease was found in the ratio of the striatal flow contralateral to chorea $(P<0.000005)$. A striking decrease was also found in the ratio of blood flow over the striatum contralateral to chorea compared with that in the control group $(P<0.000001)$. However, in a comparision of 
the ratio of blood flow in the striatum homolateral to chorea and that in the control group, there was no significant difference. In addition, the ratio of thalamic flow in patient 6 was markedly decreased in comparision with that of the other five patients.

\section{Discussion}

Non-ketotic hyperglycaemia is occasionally associated with various neurological abnormalities in which choreoathetosis is a rare manifestation. ${ }^{4-9}$ Hemichorea caused by non-ketotic hyperglycaemia was initially described by Bedwell ${ }^{4}$ in 1960 and by Rector et al, ${ }^{5}$ Tortoritis et $a l,{ }^{6}$ Sanfield et $a l,{ }^{7}$ Hann $e t a l,{ }^{8}$ and Lin $e t a l^{9}$ in subsequent years. However, these reports are of one to three patients only, whereas ours is the largest series up to now. Most cases of hemichorea or generalised chorea associated with non-ketotic hyperglycaemia develop in elderly patients with a high risk of stroke due to poor diabetic control and fluctuating blood pressure. Therefore, these patients have a greatly increased incidence of lacunar infarct involving deep cerebral structures that usually cannot be visualised on CT. However, MRI is sensitive enough to detect deep lacune and is obviously superior to CT. In our series, patients with vascular lesions located in the basal ganglia and subthalamus visible on MRI were excluded. Furthermore, patients with other conditions such as hepatocerebral degeneration, hereditary chorea, tardive dyskinesia, and hyperthroidism were also excluded. Therefore, the cause of chorea in these six patients is best ascribed to non-ketotic hyperglycaemia.

Brain PET has been sucessfully used as an indicator of local functional brain activity. The presence of striatal glucose hypometabolism shown by PET in Huntington's disease is already well established. ${ }^{12-16}$ In other entities inducing chorea, hypometabolism of the caudate nucleus and putamen was also seen, indicating that dysfunction of the striatum is relevant in the genesis of chorea and that chorea may be caused by a common pathophysiological mechanism, even though the underlying diseases are different from each other. ${ }^{1416}$ Today, PET is available in few medical centres and is not used for routine diagnosis. SPECT, evolved from PET, uses isotopes that do not require a cyclotron for their production.

The isotopes are incorporated into biologically active compounds and their distribution is plotted. Thus SPECT allows the study of focal cerebral blood flow. As with PET, the clinical potential of SPECT has yet to be recognised. Therefore, we used the SPECT technique in patients with chorea secondary to non-ketotic hyperglycaemia to assess its sensitivity in showing the presence of hyperperfusion or hypoperfusion of the striatum on the contralateral side of the chorea. From our results, decreased blood flow occurs in the striatum contralateral to the symptomatic chorea. Therefore, generalised or hemichorea due to non-ketotic hyperglycaemia possibly has a common pathogenesis of hypometabolism of the striatum as occurs in other causes of chorea. Our findings differ from the report described by Nabatame et al who first studied a patient with non-ketotic hyperglycaemic chorea. ${ }^{17}$ They used ${ }^{123} \mathrm{I}-\mathrm{N}$-isopropyl-piodoamphetamine as an isotopic agent and showed an increased blood flow in the left striatum and thalamus different from our results. However, they examined one patient only, unlike our series, and furthermore, hypoperfusion of the contralateral striatum is consistent and reproducible in our six patients. Therefore, hypoperfusion rather than hyperperfusion seems the more reliable.

Haemoglobin Alc, a fast moving minor haemoglobin component, is present in normal subjects but increases in the presence of hyperglycaemia. Normal values of $\mathrm{HbAlc}$ in a nondiabetic subject are less than $6.3 \%$ and may reach 10 to $12 \%$ in poorly controlled diabetic patients. When accurately determined, the $\%$ of $\mathrm{HbAlc}$ gives an estimate of diabetic control during the preceding three month period. In our six patients, the values of $\mathrm{HbAlc}$ are much increased, suggesting that long term poorly controlled hyperglycaemia may possibly be a major determining factor causing the choreiform movement. However, at present, we are unable to predict which patients are vulnerable to develop this kind of hyperkinetic movement. This implies that besides long term poorly controlled hyperglycaemia, a certain unidentified factor plays a critical part in causing chorea and it requires further study.

1 Martin TP, Akock NS. Hemichorea associated with a lesion of corpus luysii. Brain 1934;57:504-5.

Hyland H, Foroman DM. Prognosis in hemiballism. Neurology 1957;7:381-91.

3 Dewey RB, Jankovic J. Hemiballism-hemichorea: clinical and pharmacological findings in 21 patients. Arch Neurol 1989;46:862-7.

4 Bedwell SF. Some observations on hemiballism. Neurology 1960;10:619-22.

5 Rector GW, Herlong HF, Moses H. Non-ketotic hyperglycemia appearing as choreoathetosis or ballism. Arch Intern Med 1982;142:154-5.

6 Totoritis M, Cornish P, Thompson F. Nonketotic hyperglycemia. Arch Intern Med 1982;142:1045.

7 Sandfield JA, Finkel J, Lewis S, Roser SG. Alternating choreoathetosis associated with uncontrolled diabetes mellitius and basal ganglia calcification. Diabetes Care 1986;9: $100-1$

8 Haan T, Kremmer NPH, Padberg GWAM. Paroxysmal choreo-athetosis presenting symptoms of diabetes mellitus. $\mathcal{F}$ Neurol Neurosurg Psychiatry 1989;52:113.

$9 \mathrm{Lin}$ J, Chang MK. Hemiballism-hemichorea and nonketotic hyperglycemia. 7 Neurol Neurosurg Psychiatry 1994; 57:748-50.

10 Maccario $M$. Neurological dysfunction association with nonketotic hyperglycemia. Arch Neurol 1968;19:535-6.

11 Foster DW. Diabetes mellitus. In: Harrison's principles of internal medicine. 12th ed. New York: Mcgraw-Hill 1991: 1739-54.

12 Mazziotta JC, Wapenski J, Phelps ME, et al. Cerebral glucose utilization and blood flow in Huntington's disease: symptomatic and at-risk subjects. $\mathcal{f}$ Cereb Blood Flow Metab 1985;5(suppl 1):S25-6.

13 Leenders K, FrackowiokR, Quinn N, Marsden C. Brain energy metabolism and dopaminergic function in Huntington's disease measured by using positron emission tomography. Mov Dis 1986;1:69-77.

14 Hosokawa S, Ichiya Y, Kuwabara Y, Ayabe Z, Mitsuo K, Goto I, Koto M. Positron emission tomography in cases of chorea with different underlying diseases. $f$ Neurol Neurosurg Psychiatry 1987;50:1284-7.

15 Kuwert $T$, Lunge $H$, Laugen $K$, Herzog $H$, Aulich $A$, Feinendegen 1 . Cortical and subcortical glucose comsumpFeinendegen 1 . Cortcal and subcortical glucose comsumpease. Brain 1990;113:1405-23.

16 Otsuka M, Ichiya Y, Kuwabara Y, et al. Cerebral glucose metabolism and striatal $18 \mathrm{~F}$-dopa uptake by PET in cases metabolism and striatal $18 \mathrm{~F}$-dopa uptake by PET in cases 115:153-7.

17 Nabatame $\dot{H}$, Nakamura $K$, Matsuda M, Fujimoto $N$. Hemichorea in hyperglycemia associated with increased Hemichorea in hyperglycemia associated with increased
blood flow in the contralateral striatum and thalamus. blood flow in the contralate
Intern Med 1994;33:472-5. 